\title{
A CIDADE PERDIDA PARA AS ÁGUAS: O CASO DA VILA EPECUÉN NA PROVÍNCIA DE BUENOS AIRES, ARGENTINA
}

\section{THE CITY LOST TO THE WATERS: A CASE STUDY OF VILA EPECUÉN, BUENOS AIRES, ARGENTINA}

Lise Fernanda Sedrez*

Marina Miraglia**

Resumo: O artigo analisa a história do balneário turístico Vila Epecuén, localizado na Argentina. A vila foi destruída pela expansão das águas do lago que lhe deu o nome em 1985. Formulado na perspectiva da história ambiental para entender desastres como processos históricos socioambientais, o texto usa conceitos da Teoria Social do Risco para discutir elementos desta trajetória.

Palavras-chave: Vila Epecuén. Teoria Social do Risco. História Ambiental. Enchentes. Desastres socioambientais.

Abstract: The article analyzes the history of the tourist resort Vila Epecuén,
Argentina. The village was destroyed by the expansion of the lake after which
it was named. The article draws from the environmental history historiography
in framing disasters as social-environmental historical processes, and applies
concepts of Social Theory of Risk to focus on some elements of this case study.

Keywords: Vila Epecuén. Social Theory of Risk. Environmental History. Floods. Social-environmental disasters.

\footnotetext{
* Professora no Programa de Pós-Graduação em História Social, Instituto de História, Universidade Federal do Rio de Janeiro (UFRJ). E-mail: lise@sedrez.com

** Professora de História Ambiental na Universidad Nacional de Buenos Aires y de Sistemas de Información Geográfica na Universidad Nacional de General Sarmiento. E-mail: marina.miraglia@gmail.com
} 
No início de 1985, a Vila Epecuén era apenas um balneário procurado pelos moradores de Buenos Aires por suas águas termais e pelas amenidades turísticas. No fim do ano, já não existia mais. As águas do Lago Epecuén, que um dia foram seu maior recurso e a razão de seu sucesso, agora ocupavam as ruas da cidade. A população foi evacuada, e só podia acompanhar, pelos jornais, o avanço inexorável das águas nas ruas, nas calçadas nas casas e lojas. Oito anos depois, em 1993, o povoado de Vila Epecuén estava submerso a sete metros de profundidade. ${ }^{1}$

Mas a história não termina aí. A partir do final do século XX e início do século XXI, as águas começaram a recuar. Trinta anos depois do desastre que a submergiu, Villa Epecuén pode ser vista como uma cidade fantasma ou uma Atlântida argentina, com suas ruínas agora acima do nível das águas.

Um estudo da criação, perda e — literalmente — reemersão de Vila Epecuén na paisagem argentina é uma instigante janela para as relações entre natureza e sociedade. Nosso artigo traça a história de Vila Epecuén, buscando entender os processos decisórios de ocupação do território, e como eles se entrelaçam com os ciclos e as dinâmicas da natureza na região. Por um lado, a trajetória da Vila Epecuén é uma cautionary tale, um testemunho da importância de conhecer as oscilações climáticas, a fim de planejar adequadamente o manejo do território urbano. Foi este desconhecimento que fez com que vila fosse sepultada em $1985 \mathrm{sob}$ as águas do lago de mesmo nome. Mas por outro lado, o estudo é também uma oportunidade de entender os ritmos de ocupação territorial, e sua interdependência com os ritmos dos ecossistemas locais e globais.

\section{A VIDA E A MORTE DE VILA EPECUÉN}

A Vila Epecuén existia em função do Lago Epecuén. As águas mineralizadas do lago eram utilizadas para tratamento de doenças reumáticas e dermatológicas ou como tonificantes. A primeira referência ao Lago Epecuén foi feita em 1780 por Pablo Zizur, piloto da Real Marinha de Espanha. Com a ocupação do território indígena pelo Estado argentino, a tradição oral e os comentários entusiastas já atraíam visitantes de outras regiões do país para se banhar no lago. Em fins do século XIX, a chegada da ferrovia à pequena cidade de Carhué, às margens do lago, trouxe também uma febre turística, com a proliferação de grandes hotéis e comércio. Em 1909, a província de Buenos Aires enviou uma comitiva de especialistas ao lago para dar respaldo médico-científico a seus protestos de águas milagrosas. A década de 1920 foi decisiva para o futuro do Lago Epecuén, que viria a se tornar o maior centro de águas termais da Argentina. Em 1921, surgiu o primeiro balneário às suas margens, o "Mar de Epecuén", a oito quilômetros de Carhué, acompanhado de 
forte especulação imobiliária e o imediato loteamento das terras ao seu redor para formar uma cidade.

Figura 1 - Anúncio de vendas de lotes na Vila Epecuén, 1935

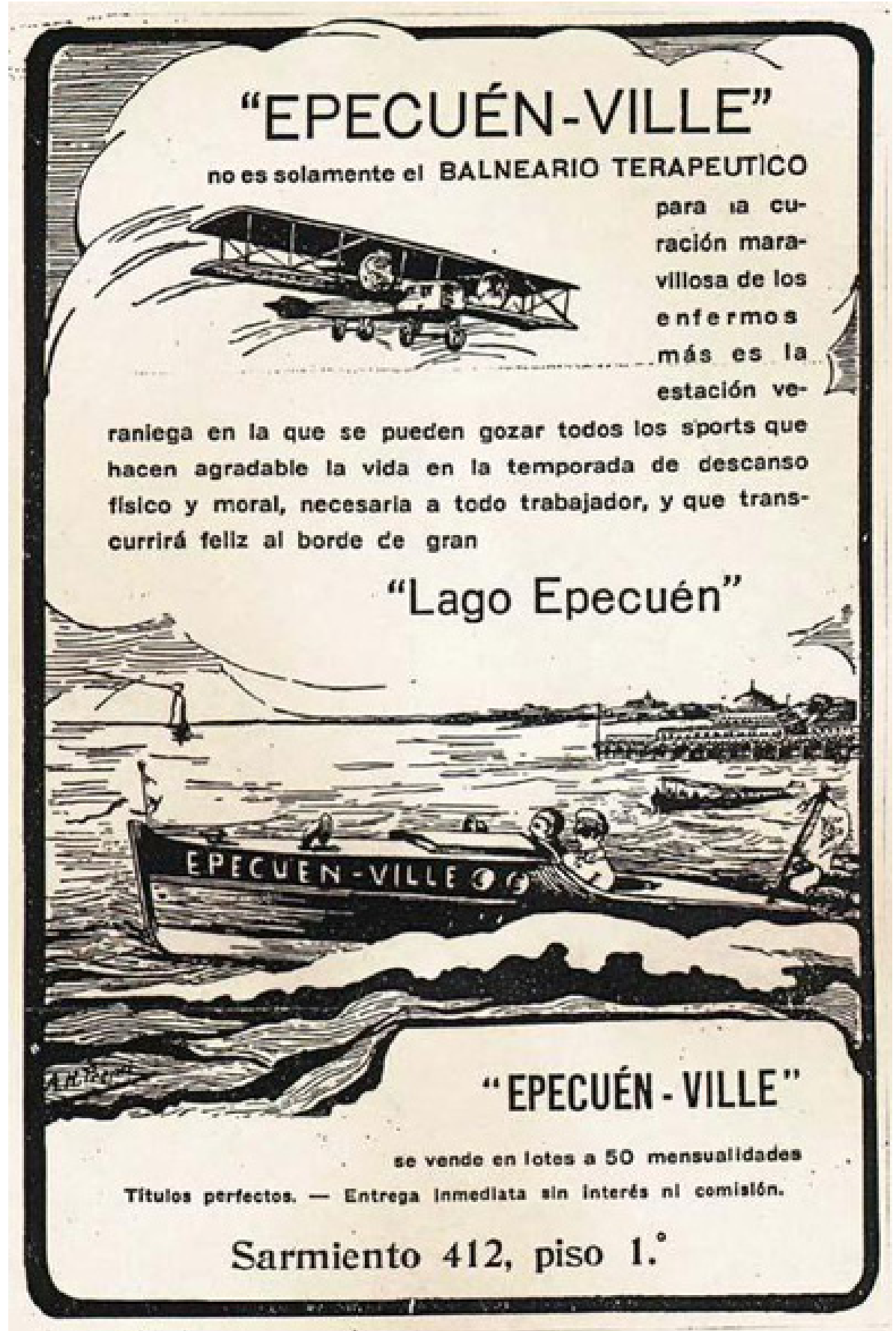

Fonte: Museo Regional Dr. Adolfo Alsina. Carhué, Buenos Aires, Argentina. Disponível em: $<$ http://www.museocarhue.gov.ar/imgepecuen3.htm>. 
De fato, na década de 1920 vislumbrava-se um grande futuro para o Lago Epecuén. Atendendo a esta visão, empresários apressaram-se em investir em uma miríade de obras cujo fim era oferecer conforto e serviços termais, que até então não existiam na região dos pampas, aos banhistas de Buenos Aires e Bahía Blanca. Em Buenos Aires, a vila turística era promovida por suas propriedades terapêuticas e esportivas e se comercializavam terrenos no local. Grande número de visitantes chegava de Buenos Aires por meio das ferrovias - a Ferrovia Sarmiento servia a estação Vila Epecuén, enquanto a Ferrovia Midland e a Ferrovia do Sul levavam passageiros até a estação Carhué.

O ritmo de crescimento foi extraordinário. Hotéis e molhes foram construídos inclusive dentro do lago, além de residências luxuosas e empresas exploradoras de sal e da venda de barros e sabões curativos. A indústria turística não era apenas de serviços, mas contava com uma produção significativa de mercadorias para atender aos visitantes. Na década de 1930, a Vila Epecuén tinha não só hotéis, mas também trabalhadores e proprietários envolvidos nas múltiplas ramificações da indústria turística. A malha urbana também se compunha de igreja, escolas e todas as estruturas necessárias para o desenvolvimento de uma cidade. A população estável da Vila continuou pequena, mesmo no seu apogeu, mas no período turístico a população flutuante multiplicava por um fator de vinte o número de pessoas. Com cerca de 1.500 moradores permanentes, a Vila Epecuén chegou a contar, no início da década de 70, com 5 mil leitos de hotel registrados e 2 mil vagas informais. Eram 280 estabelecimentos, entre hospedarias, pensões, hotéis e comércios, que chegaram a receber, nas décadas de 1950 a 1970, 25 mil turistas de novembro a março.

A Vila Epecuén está a cerca de $570 \mathrm{~km}$ da região metropolitana de Buenos Aires, na bacia das Lagoas Encadeadas do Oeste da província de Buenos Aires, a cerca de quinze quilômetros da cidade de Carhué, sede do distrito de Adolfo Alsina. A Subsecretaria de Recursos Hídricos da Nação estudou a bacia das Encadeadas dentro da chamada região lacustre do Sudoeste de Buenos Aires, com uma superfície de 3.066 .800 hectares. ${ }^{2} \mathrm{~A}$ área limita-se ao norte com outra região sem deságue para o mar, na província de La Pampa; a leste, com a bacia do Rio Salado de Buenos Aires; e a sul com a bacia de riachos do sul de Buenos Aires e afluentes atlânticos. Essa última bacia envolve cinco distritos da província de La Pampa (Atreuco, Guatraché, Hucal, Lihuel Calel e Utracán) e sete da província de Buenos Aires (Adolfo Alsina, Coronel Suárez, Daireaux, General La Madrid, Guaminí, Puán e Saavedra), como mostra o mapa abaixo. 


\section{Mapa 1 - Localidade da Bacia Encadenadas del Oeste, na} Província de Buenos Aires

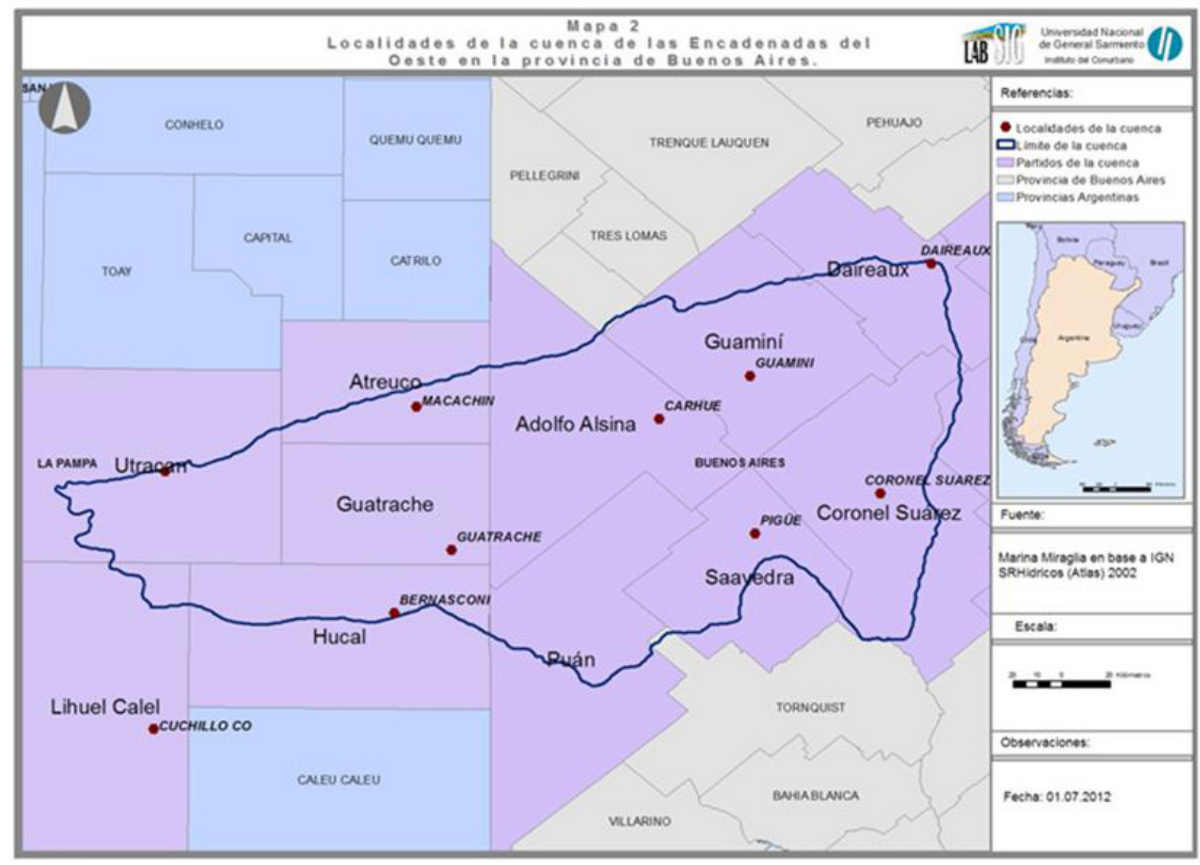

Fonte: MIRAGLIA, Marina. La historia ambiental y los procesos de construcción territorial de dos cuencas hidrográficas de la provincia de Buenos Aires (1776 y 2006). Tese (Doutorado em Geografia), Universidade de Buenos Aires, Buenos Aires, 2013.

As qualidades minerais do Lago Epecuén se devem às suas características ambientais. O lago não tem pontos de deságue para outra bacia ou para o mar. Recebe excedentes de água por chuvas e córregos e, na seca, evapora esses excedentes. Esta decantação é responsável pela sua salinidade e mineralização naturais únicas.

Por mais de 60 anos, o lago, agora com esta peculiar fauna de turistas, prosseguiu com sua rotina de cheias e secas, seguindo seu comportamento milenar. Mas esta dinâmica era por demais instável para os investidores. Os proprietários de hotéis dependiam das boas chuvas para que a água ficasse próxima aos molhes e aos serviços - e para que se dissolvesse o manto de sal, o que é era necessário para um banho agradável. Em temporadas de secas, as chuvas eram por demais escassas para obter os resultados desejados. Então as temporadas turísticas fracassavam. As alternativas eram pouco atraentes: abrir poços para filtrar a água e eliminar o excesso de sal, permitindo os mergulhos, acabava por afastar os turistas que buscavam Epecuén justamente pelas águas termais benéficas à saúde.

Quando, em 1962, a região passava por uma estiagem severa e as lagoas (principais atrações turísticas da região) estavam quase secas, os moradores e empresários do turismo local demandaram do governo provincial que 
construísse um canal para alimentar as lagoas com água das serras para que recuperassem seu volume e não se perdesse a renda gerada pelo turismo. Havia que se estabilizar o caudal da lagoa, providenciando um fornecimento constante que compensasse a carência de chuvas dos períodos secos. A natureza, generosa ao fornecer as águas termais, era pouco confiável para os projetos capitalistas. A engenharia e a tecnologia podiam garantir isto. Entre 1965 e 1975, as autoridades provinciais responderam às muitas reinvidicações dos empresários de Epecuén, e construíram o Canal Ameghino, que, por alguns anos, cumpriu satisfatoriamente sua missão para os habitantes das Encadeadas. Outras obras hidráulicas foram inciadas em 1972, mas foram interrompidas pelo golpe de estado de 1976, que substituiu Isabel Perón por uma junta militar, inciando a ditadura militar argentina. Até aquele momento, só o Canal Ameghino, que coletava águas de outra bacia hídrica, fora terminado.

As reivindicações por fontes de água constantes, independente dos caprichos da natureza, estão claramente relacionadas à percepção de incerteza dos atores sociais da bacia hidrográfica. Como afirma Claudia Naterzon:

Quando falamos de incerteza, porém, estamos falando da visão da sociedade e de como toma decisões com relação aos problemas que enfrenta. Os eventos e os aspectos incluídos estão vinculados à heterogeneidade social; ao Estado, em diferentes níveis; às organizações não governamentais, tradicionais e novas; à sociedade civil em seu conjunto, que dinâmica assume, que tradições têm; aos organismos internacionais que incidem ou não na definição de políticas públicas, até que ponto incidem ou não na tomada de decisões de política interna; os meios de comunicação, as representações corporativas, sindicatos, militares, empresários, partidos políticos. ${ }^{3}$

Mas se o problema que incomodava os empresários de Epecuén era pouca chuva, nos anos 80 a situação se reverteu. No momento de construir o canal a região atravessava uma grande estiagem, dentro de um ciclo climático sub-úmido. No final da década de 1970, no entanto, a Argentina começou a viver um ciclo climático úmido, que produziu fortes precipitações, como as de 1978, 1980, 1985, 1992 e 1993. Em 1985, o Canal Ameghino continuava levando água para as lagoas, indiferente à mudança das condições climáticas. De fato, no momento da construção do canal não se havia analisado a possibilidade de ocorrência de um ciclo úmido e como se comportaria o Sistema das Lagoas Encadeadas ao receber mais água do que era capaz de receber sem entrar em colapso. Além deste, outro aspecto negligenciado foi a regulação das águas dos córregos Huáscar e Sauce Corto para os momentos pico de cheia. Por omissão ou negligência, não se levou em conta a relação entre o sistema das Encadeadas 
com as cheias dos arroios das serras, os quais, antes da construção do canal, desaguavam diretamente no Vallimanca.

As abundantes chuvas de 1980 transformaram o canal de uma benfeitoria em um risco. Se o canal trazia águas de outra bacia em época seca, em períodos úmidos estas águas eram excessivas. Era necessário um dique para defender a cidade da possibilidade de inundação. A engenharia trouxera não a esperada estabilização, mas uma nova instabilidade, pelo descompasso com os ciclos de secas/chuvas da região. E esta nova instabilidade agora ameaçava a cidade.

Como o Lago Epecuén é o último lago, e também o mais baixo, do chamado sistema de Lagoas Encadeadas do Sudoeste, ele não tem nenhuma saída para o grande vale em que se encontra. Monachesi descreve assim o avanço do ciclo úmido:

Durante o prolongado período de estiagem, construiu-se um canal - entre outras obras - para levar água a estas lagoas, com base no interesse pelo turismo termal e pela pesca esportiva. Os trabalhos foram finalizados assim que começou o ciclo úmido. Com as inundações na região, devidas ao transbordamento das lagoas, em alguns casos foram ameaçados os povoados assentados às suas margens (Epecuén, Guaminí), alagaram-se campos e se elevaram notavelmente os lençóis freáticos, afetando cerca de 20 mil hectares entre 1978 e $1980 .{ }^{4}$

Estes fatores, entre outros desconhecidos, provocaram a saturação do sistema das Lagoas Encadeadas. Ao receber aportes hídricos extraordinários, que não estavam em condições de absorver, transbordaram, especialmente o Lago de Epecuén. Entre 1980 e 1985, as chuvas e a entrada de água sem controle pelo canal foram condenando o povoado de Vila Epecuén, que só sobrevivia porque estava protegido por uma muralha de quatro metros de altura. Em 1985, apesar de um forte alerta de 1978, os efeitos chegaram a seu ponto máximo. Em 10 de novembro, o enorme caudal de água rompeu o dique de pedra e terra e inundou grande parte da localidade. A Vila do Lago Epecuén desapareceu. Em 1986, o povoado tinha quatro metros de água em suas ruas, chegando em 1993 a mais de dez metros. ${ }^{5}$

As inundações provocadas pelo transbordamento das Lagoas Encadeadas afetaram principalmente os espaços urbanos dos distritos de Adolfo Alsina, Guaminí e Daireaux. O desaparecimento de Epecuén e do cemitério de Carhué sob as águas causou graves transtornos ao turismo local, deteriorando as fontes de trabalho regionais e provocando a migração populacional para outras cidades. R. Gurevich descreve o debate que se seguiu ao desastre: 
Foram várias as propostas estudadas depois da 'grande inundação' (como é chamada pelos habitantes). Em termos de infraestrutura, propôs-se: transferir a cidade de Carhué para uma cota mais elevada; desviar a água excedente de Epecuén para outras lagoas; fazer outro canal para levar a água a Bahía Blanca; e, também, reflorestar as margens do Lago de Epecuén com espécies arbóreas de alta capacidade de evaporação e transpiração. Aúltima grande obra pública executada (1994) foi o trabalho de bombas holandesas e estadunidenses na área. Em termos de apoio orçamentário, as respostas mais frequentes foram isenções ou moratórias fiscais, linhas de crédito e refinanciamento das dívidas contraídas. $^{6}$

Em 1985, a Argentina não estava, porém, em situação de seguir muito fielmente esta agenda. Recém-saída da ditadura militar, às voltas com as consequências de outro desastre, este militar, da Guerra das Malvinas em 1982, o país se encontrava num momento de reestruturação da situação políticoinstitucional. Como afirma Naterzon, os partidos políticos avançavam na construção de uma democracia incipiente, e "tiveram um papel muito ativo, sobretudo, nos abrigos para refugiados; para organizar, para melhor, para demandar." Especialmente no caso de Epecuén, porém, "o papel ativo esteve com os grupos sociais de classe média", devido à sua capacidade de peticionar as autoridades para "reclamar, organizar as pessoas ou assumir certa liderança de grupo". ${ }^{7}$ Ao mesmo tempo, os empresários de Epecuén tinham que disputar a atenção desta democracia incipiente com outras agendas igualmente prementes. Em 1985, por exemplo, os primeiros grandes julgamentos de participantes do regime militar estavam se iniciando - o general Emílio Massera fora então condenado à prisão perpétua, num processo que recebeu enorme publicidade. Em junho do mesmo ano, o presidente Raul Alfonsín ousadamente adotou uma nova moeda para a Argentina, o Austral, buscando com isto reencaminhar a economia argentina e controlar os processos inflacionários. E como se isto não bastasse, os ciclos úmidos não atingiram somente Epecuén. Em 1985 houve nada menos que três grandes enchentes na província de Buenos Aires somente, em fevereiro, em junho e em novembro, sendo que a de junho forçou a remoção de cerca de 100 mil pessoas em toda a província de Buenos Aires.

A história de Vila Epecuén, portanto, não pode ser vista fora de um contexto argentino de ocupação de território. Isto se refere não só ao seu momento mais espetacular - a inundação em 1985 - mas a todo o processo de escolhas e estratégias de ocupação que fez com que a vila fosse criada. Nas próximas páginas, sugerimos que, inicialmente, a trajetória de Vila Epecuén pode ser analisada no âmbito de uma teoria social do risco. Em segundo lugar, propomos que, sendo uma vila em área eminentemente rural, mas atendendo 
a uma população flutuante de turistas, basicamente urbana, Vila Epecuén desenvolveu uma história ambiental urbana própria, em que as pressões urbanas externas se misturam com as condições locais de ocupação de território.

\section{TEORIA SOCIAL DE RISCO}

As inundações reconhecidamente constituem o problema ambiental de maior recorrência na Argentina, em particular na Região Metropolitana de Buenos Aires (RMBA) desde 1960, assim como em toda a província de Buenos Aires, devido a fenômenos ou eventos naturais potencializados por ações não naturais. Como afirma Morello, essas ações geraram, no sistema periurbano (interface ecológica entre o campo e a cidade), a anulação ou redução dos serviços ambientais ou ecológicos propiciados pelo campo (regular o fluxo de água, absorver, reter e distribuir fluxos pluviais de curta duração etc.). ${ }^{8}$ Os processos humanos interferem nos ciclos hídricos de várias formas, desde a diminuição da amplitude do vale de inundação, a canalização dos rios em galerias subterrâneas, a mudança na profundidade dos leitos normais e a intensificação ou atenuação das inundações em várias zonas, através a construção de defesas costeiras.

Ao lado destas intervenções sociais, historicamente na Argentina produziram-se de forma alternada ciclos climáticos úmidos e secos-dentro dos quais apareceram tanto eventos de inundações como de secas..$^{9}$ É importante, portanto, interpretar os fenômenos desse tipo, assim como suas relações com a sociedade que intervém sobre eles. É nesta perspectiva que a teoria social do risco pode sugerir uma análise fértil. De acordo com Natenzon e González, "a abordagem desse tipo de problemas - complexos, dinâmicos, urgentes - pode realizar-se a partir de pelo menos quatro dimensões: em relação à causalidade dos processos físico-naturais; em relação aos constructos sócio-territoriais e sua distribuição; com respeito à estrutura socioeconômica; e considerando valores, visões e perspectivas gerados por diferentes grupos sociais sobre eles". ${ }^{10}$

Segundo as diretrizes teórico-metodológicas apresentadas por Claudia Natenzon, a teoria social do risco é aplicada para a análise de processos catastróficos como as inundações, caso deste estudo. Esta teoria tem seu eixo central no conceito do risco social. Há risco quando se pode quantificar, caso contrário estamos em presença da incerteza. Para Naterzon,

O risco também pode ser definido como um resultado imprevisto que sucede como consequência de nossas próprias atividades ou decisões e não por obra divina, acaso ou fatalidade. [...] Esta postura desloca o interesse ou o foco de interesse do que seria uma situação fatal (que até na Idade Média era pensada como uma questão divina) 
para a própria responsabilidade, para a reflexão que posso fazer sobre o que acontece ao redor e para as decisões que se podem tomar a respeito. ${ }^{11}$

Neste sentido, incorporar essa diretriz teórico-metodológica permite considerar quatro aspectos constitutivos da análise das catástrofes: periculosidade, exposição, vulnerabilidade e incerteza.

Quadro 1 - Teoria Social do Risco

\begin{tabular}{|c|c|}
\hline FATORES/ \\
PERSPECTIVAS & CONHECIMENTO NECESSÁRIO \\
\hline $\begin{array}{c}\text { PERICULOSIDADE } \\
\text { Potencialidade }\end{array}$ & $\begin{array}{c}\text { Aspectos físico-naturais do evento ou processo } \\
\text { natural disparador. }\end{array}$ \\
\hline $\begin{array}{c}\text { EXPOSIÇÃO } \\
\text { Impacto material }\end{array}$ & $\begin{array}{c}\text { Aspectos territoriais e populacionais (número de } \\
\text { pessoas, bens, sua distribuição). }\end{array}$ \\
\hline $\begin{array}{c}\text { VULNERABILIDADE } \\
\text { Estruturas sociais }\end{array}$ & $\begin{array}{c}\text { Aspectos socioeconômicos comprováveis do } \\
\text { estado anterior dos grupos sociais envolvidos. }\end{array}$ \\
\hline $\begin{array}{c}\text { INCERTEZA } \\
\text { Percepção, decisões }\end{array}$ & $\begin{array}{c}\text { Aspectos políticos e de percepção dos grupos } \\
\text { sociais envolvidos. Valores e interesses em jogo. }\end{array}$ \\
\hline
\end{tabular}

Fonte: NATENZON, 1998. ${ }^{\mathbf{1 2}}$

A periculosidade refere-se à potencial ameaça dos fenômenos físicos e a exposição, às construções materiais e à distribuição da população no território. O tipo de relação estabelecida entre estes fatores pode apresentar desequilíbrios quanto à sustentabilidade do ambiente, aos seus componentes sociais e físico-naturais.

A pergunta seguinte, portanto, seria quais foram os processos físiconaturais que participaram do processo histórico de construção dos territórios urbanos e rurais na província de Buenos Aires? Os graves problemas ambientais desta bacia, particularmente as inundações, são vistos então como resultado das relações historicamente estabelecidas entre os fatores físico-naturais e os atores sociais, que configuraram territorialmente essa bacia, com as presentes condições específicas de risco para suas populações e para o ambiente. As chuvas copiosas, o transbordamento de corpos e cursos d'água e os alagamentos de terrenos são considerados catastróficos, na medida em que esses processos naturais afetam uma sociedade.

No caso da Vila Epecuén, as chuvas intensas de 1985, dentro de um ciclo climático úmido na região, provocaram, associadas a obras de engenharia 
hidráulica que não contemplaram a dinâmica hídrica da bacia, as inundações das áreas urbanas de Carhué, Epecuén e Guaminí.

\section{O PROCESSO DE CONSTRUÇÃO TERRITORIAL}

A estruturação do território, entendido como um sistema complexo, e sua sustentabilidade são parte dos processos cotidianos de reprodução da vida dos atores sociais que vão construindo articuladamente, num território, com suas ações e práticas, não apenas o quadro de suas próprias vidas, mas também a sociedade, a cidade e a sustentabilidade em seu conjunto. ${ }^{13}$ Esta articulação entre sociedade e território aparece mediada por elementos, processos e atores sociais, num sistema onde relações sociais específicas produzem sua sustentabilidade e a diferenciação sócio-espacial.

$\mathrm{Na}$ bacia em questão, o processo de conformação territorial rural apresenta características específicas que resultam de sua ocupação histórica. Em primeiro lugar, os principais eixos de expansão rural foram as vias concessionárias e não o traçado da ferrovia. Nesta expansão, a região não se estendeu de forma homogênea ou contínua, mas cresceu especificamente nos grandes empreendimentos produtivos, com a intensificação dos investimentos de capital produtivo. O capital privado se encarregava então de organizar partes importantes do território produtivo, dedicadas basicamente à atividade agropecuária, e realizar os investimentos de capital e tecnologia. Isto fez com que a região experimentasse em meados do século XX um processo de expulsão da população rural em direção às localidades dessas bacias hidrográficas ou em direção à região metropolitana de Buenos Aires, em Mar del Plata ou em Bahía Blanca, com a consequente despovoação na área rural. ${ }^{14}$

Tanto o Estado como os grupos investidores de capital colaboraram nas concessões dos serviços públicos para as áreas consolidadas e nos novos empreendimentos urbanos, comerciais e industriais. Por outro lado, o Estado também oferecia subvenções aos concessionários de serviços públicos e elaborava planos assistenciais para os grupos sociais mais vulneráveis, localizados em vilas, assentamentos, terras públicas e terrenos ocupados.

Tanto nos povoados consolidados como nos novos territórios incorporados à área urbana encontram-se situações onde as populações de baixos e altos recursos se agrupam, organizando e conformando vastas áreas. Se observadas articuladamente, a dimensão espacial e a socioeconômica se sobrepõe: é possível localizar nos mapas as áreas de ocupação e desocupação, que se associam a variáveis como trabalho precário, acesso à educação, analfabetismo, uso de internet, uso de automóvel, indigência, acesso à serviços, belezas naturais, ocupação de terras altamente valorizadas, etc. ${ }^{15}$ 
Para Lombardo, o espaço urbano é concebido, de um lado, como uma das dimensões do sistema de reprodução da sociedade em questão e, por outro, como o lugar onde se operacionalizam as relações de reprodução dos atores que o formam. ${ }^{16} \mathrm{Da}$ mesma forma, pode-se incorporar o espaço rural. Essas dimensões - o social, o espacial, o econômico, o ambiental, o político etc. atuam de forma inter-relacionada em cada situação de reprodução concreta dos atores num território.

As diversas estratégias, ações e mecanismos de cada um desses atores, articuladas nesse contexto, se apropriam de espaços próprios no território. Assim constituem os espaços e infraestrutura que os conformam como suporte dos diversos circuitos de atores envolvidos e das relações que se constituem.

É este processo de apropriação de espaços que nos interessa compreender, na bacia das Encadeadas. Grande parte das localidades teve sua origem como estações ferroviárias da companhia Midland ou como postos avançados na Conquista do Deserto no século XIX, como é o caso de Guaminí e Carhué. Do mesmo modo, os usos urbanos e agropecuários do solo também influenciaram na configuração atual da dinâmica ambiental. Os primeiros povoadores e visitantes chegaram ao lugar em galés ou diligências que vinham dos municípios de Azul, 25 de Maio e, em anos posteriores, Arroyo Corto, que era terminal da Ferrovia do Sul. Em 1899, chega a Ferrovia do Sul e, quatro anos mais tarde, a Ferrovia Oeste, em 1903, com paradas em Carhué e Epecuén. Alguns anos mais tarde, em 1911, chega a Ferrovia Midland de Buenos Aires (Puente Alsina-Carhué), que baseia sua publicidade essencialmente nos benefícios das águas do lago e na rapidez de seus serviços.

O desenvolvimento espacial das cidades avançou nas últimas décadas do século XX até as margens das lagoas e dos rios, acrescentando a vulnerabilidade dos habitantes dessas zonas à inundação ocasionada pelo transbordamento dos corpos e cursos d'água. Vulnerabilidade deve ser entendida de uma forma ampla, uma categoria historicamente construída que depende de múltiplos fatores, ao mesmo tempo diversos e interdependentes. Para Claudia Naterzon, vulnerabilidade "tem a ver com as estruturas econômicas anteriores." Naterzon continua:

Os eventos, processos e relações incluídos são: as estruturas sociais, econômicas e políticas da sociedade afetada, e as relações de escala que se estabelecem entre essas estruturas. As características a considerar são: qual base produtiva tem essa sociedade; como é a posse da terra; qual capital se acumulou ou não; qual desenvolvimento tem o capital financeiro; de qual tipo de capital financeiro se trata - se é privado ou estatal; os processos demográficos da população, se é jovem ou se é envelhecida; as relações de trabalho e do consumo; a distribuição de renda; qual tecnologia é 
utilizada, qual tecnologia se oferece no lugar, qual está disponível; qual é o quadro normativo e as instituições que estão organizando sua aplicação; quais são as regras do jogo que essa sociedade reconhece e se funcionam ou não; que regulamentações devem seguir; quais são as instituições públicas, seus organogramas, missões e funções. ${ }^{17}$

\section{O SURGIMENTO DE OUTRO BALNEÁRIO: A HISTÓRIA CONTINUA}

Vinte anos depois da Grande Inundação, o ciclo úmido dera lugar a um período de secas. Por volta de 2005, a falta de chuvas estava afetando a região de Epecuén e, com isso, as águas do lago foram baixando. Essa retração contínua permitiu que a antiga vila turística começasse a ressurgir das profundezas. Segundo Mariano Naggy, naquele ano era possível caminhar pelas ruínas do povoado, já que a água continuava baixando cada vez mais. ${ }^{18}$

Naggy, diretor do museu de Carhué, menciona que, devido às mudanças climáticas, a cidade de Carhué, que de certa forma herdara os turistas de Epecuén após 1985, estava tendo prejuízo. As reclamações pareceriam familiares para quem se recordasse dos empresários de Epecuén nos anos 60: as águas muito longe das instalações turísticas, excesso de sal em áreas de banho, as paisagens menos atraentes para os que buscavam mergulhos de verão no lago. Mas desta vez, ao invés de conceber um novo canal que regulasse as águas, as autoridades municipais de Carhué imaginaram que poderiam aproveitar o ressurgimento da Vila Epecuén como novo ponto turístico. Para isto, seria criado o Museu Histórico de Epecuén na antiga estação ferroviária, com visitas guiadas, filmagens e fotos de época. Seria cobrada uma entrada simbólica para gerar renda para o tesouro municipal e para socorrer a economia do turismo, a fim de que não fosse tão afetada pelo baixar das águas. ${ }^{19}$

Ao longo da década seguinte, as águas continuaram baixando, descobrindo então completamente os restos ocultos da Vila de Epecuén. O turismo do desastre é agora quase tão crucial para a economia da cidade de Carhuén como os tradicionais turistas que buscam o lago e as águas termais. Caminhar pela cidade fantasma é parada obrigatória para os visitantes do Lago Epecuén. 
Figura 2 - O matadouro municipal

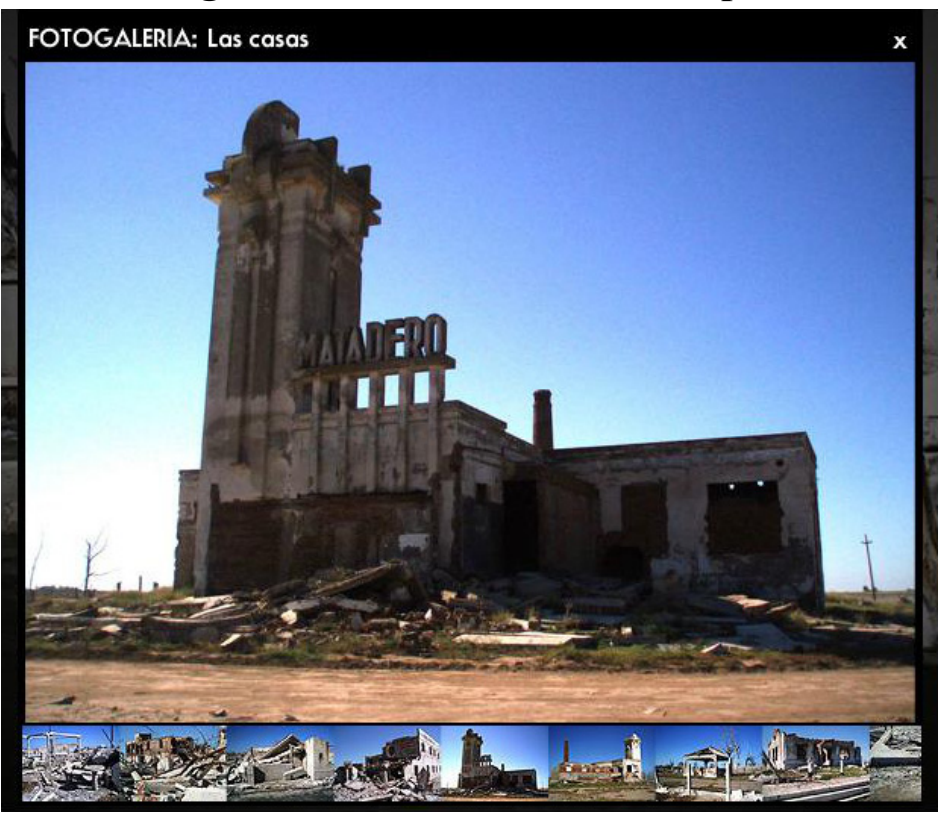

Fonte: GIAMBARTOLOMEI, Maurício (coord). Sobre Las Ruinas de Epecuen. Información General. La Nación, Buenos Aires, 4 jun. 2010. Disponível em: <http://www.lanacion.com.ar/1271457epecuen-el-pueblo-que-emergio-de-las-aguas $>$.

Figura 3 - Os restos de umtitua casa

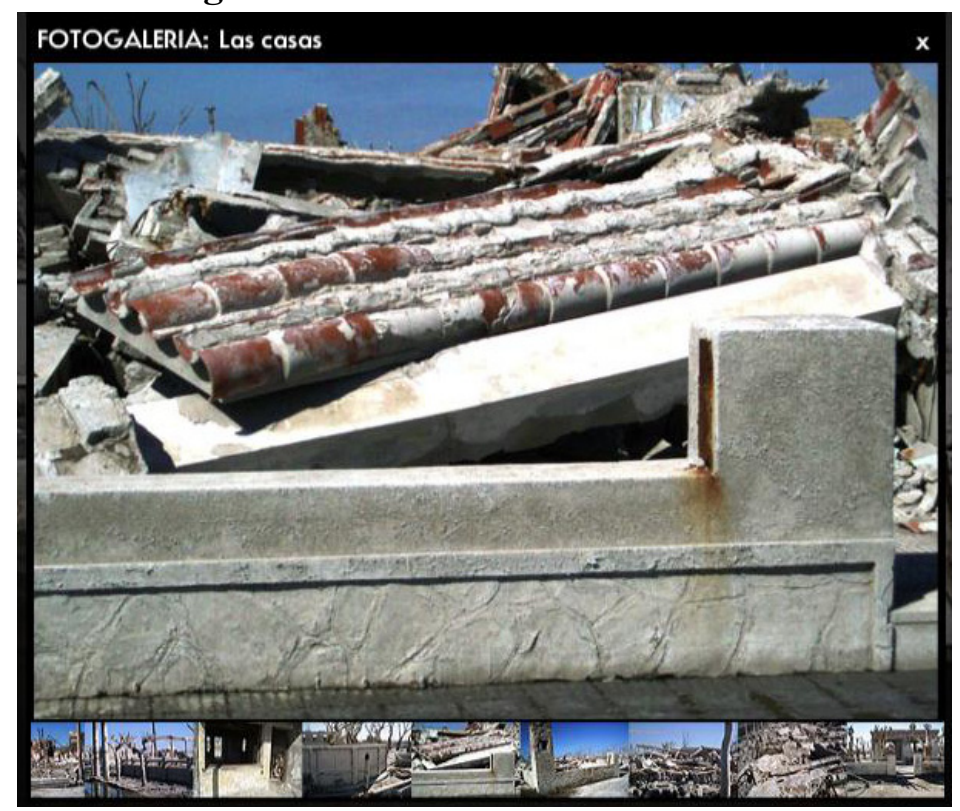

Fonte: GIAMBARTOLOMEI, Maurício (coord). Sobre Las Ruinas de Epecuen. Información General. La Nación, Buenos Aires, 04 jun. 2010. Disponível em: <http://www.lanacion.com.ar/1271457epecuen-el-pueblo-que-emergio-de-las-aguas $>$. 


\section{CONCLUSÃO}

A história de Epecuén ecoa muito dos processos de construção territorial na América Latina, caracterizados por uma forte interrelação entre os recursos naturais e a sociedade, através de padrões socioeconômicos de exploração daqueles. Esses padrões são dados pelos modelos político-econômicos dominantes em cada período histórico e pela incorporação da América Latina ao sistema capitalista internacional.

Os processos de urbanização provocaram a alteração do escoamento das águas, a impermeabilização dos solos, a destruição da cobertura vegetal nativa e a substituição da fauna autóctone. Por outro lado, geraram efeitos negativos nas sociedades, tais como inundações, contaminação, erosão e salinização dos solos, com a consequente perda da capacidade produtiva e da eutrofia dos solos e dos cursos d'água, poluídos por efluentes industriais, agropecuários e residenciais.

A urbanização deste território tem sido causa de grandes debates entre estudiosos. Para Cunill Grau, a contínua expansão das áreas urbanas das cidades latino-americanas não tem planejamento ou limites. ${ }^{20}$ Estas áreas urbanas se afastam cada vez mais do núcleo urbano histórico, devido às novas concepções de residências de renda média e alta em subúrbios exclusivos, assim como de consolidação de espaços para trabalhadores de baixa renda.

Epecuén era porém um tipo diferente de área urbana. Não se tratava exatamente de um subúrbio ligado a uma grande cidade latino americana. Mas como espaço de lazer, de temporada turística, estava sem dúvida ligada a esta expansão da influência da cidade, estabelecendo com Buenos Aires uma continuidade sócio-econômica, tão importante quanto a descontinuidade espacial.

$\mathrm{Na}$ perspectiva nacional, Epecuén deve ser entendida no processo de expansão territorial argentino, relacionado tanto aos investimentos em infraestrutura ferroviária e portuária, como à grande imigração europeia que contribuiu para o desenvolvimento demográfico e o crescimento das cidades. A partir da década de 1930, o crescimento acelerado das cidades as converte em fundamentais pólos de atração por seus recursos econômicos e sociais. Esse foi o caso da região metropolitana de Buenos Aires, caracterizada pela concentração de população e pela polarização das atividades administrativas, financeiras, bancárias, comerciais e culturais, aspectos que consolidaram um forte desequilíbrio espacial. O alcance destes pólos urbanos se extendia muito além do seu território legal, e o impacto ambiental de Buenos Aires podia ser percebido em localidades tão distantes como Epecuén. ${ }^{21}$

As práticas de construção territorial, sem conhecimento da periculosidade, do risco, da vulnerabilidade e da incerteza das populações locais, diante de fenômenos físico-naturais, como os ciclos regionais de seca/chuvas, geram 
respostas pouco adequadas às realidades próprias de cada região e de cada grupo de atores sociais envolvidos no processo. No caso da Vila Epecuén, recursos hídricos foram desviados para o Lago Epecuén sem conhecimento das oscilações climáticas próprias da bacia hidrográfica. Agora, num período seco, as águas baixam e a vila volta a ser oferecida como atrativo turístico, já não por suas capacidades hoteleiras e sim por sua condição de "ressurgida das profundezas", tomando o desastre como eixo para a captação de turistas. Tampouco se sabe até quando será possível fazer esses "passeios sobre o desastre", pois as águas do lago podem voltar a subir num novo ciclo úmido e cobrir os restos da vila novamente. Resta saber qual será a metáfora mais adequada à Vila Epecuén: Atlântida ou Perséfone argentina?

\section{NOTAS}

${ }^{1}$ Buenos Aires Turismo. Termas de Carhué en Buenos Aires, Argentina. Disponível em: <http:// www.buenosairesturismo.com.ar/termas-carhue.htm>. Acesso em: 12 mar. 2014.

${ }^{2}$ Ver o Atlas Digital de Cuencas y Regiones Hídricas Superficiales de la República Argentina. Disponível em: <http://www.hidricosargentina.gov.ar/CartAct.html>. Acesso em: 14 mar. 2014.

${ }^{3}$ NATENZON, Claudia. Riesgo, vulnerabilidad e incertidumbre. Desastres por inundaciones en Argentina. Exposición realizada en el Seminario sobre "Problemas ambientales e vulnerabilidade. Abordagens integradoras para o campo da Saude Publica". Dictado el 25 de junio de 1998, na Fiocruz, Ministério da Saúde, Rio de Janeiro, Brasil, 1998.

${ }^{4}$ MONACHESI, Alejandra. Las inundaciones en el sudoeste de la provincia de Buenos Aires, Argentina: un problema de actores y estrategias. Desastres y Sociedad, n. 5, v. 3, 1995.

${ }^{5}$ MIRAGLIA, 2013, op. cit. e MONACHESI, 1995, op. cit.

${ }^{6}$ GUREVICH, Raquel. Inundaciones en el sistema de las lagoas encadenadas. Notas acerca de cómo segestiona la complejidad. Desastres y Sociedad, n. 5., v. 3, p. 1-15, jul./dec. 1995.

${ }^{7}$ NATENZON, op. cit.

${ }^{8}$ MORELLO, Jorge. Funciones del sistema periurbano: el caso de Buenos Aires. Mar del Plata: Universidad Nacional de Mar del Plata-Ediciones CIAM-GADU, 2000.

${ }^{9}$ AMEGHINO, Florentino. Las secas y las inundaciones en la provincia de Buenos Aires. Buenos Aires: Editorial Lajouane, 1886; DURÁN, D. Sequías e inundaciones. Propuestas. Buenos Aires: Editorial Oikos, 1987; e MIRAGLIA, Marina. Diagnóstico ambiental de la cuenca de las Encadenadas del oeste de la pcia. de Buenos Aires. Bases históricas preliminares para el manejo de los recursos naturales del partido de Adolfo Alsina. Pcia. de Buenos Aires. Buenos Aires, Informe final de Beca de Perfeccionamiento del CONICET, 1996.

${ }^{10}$ NATENZON, Claudia E.; GONZÁLEZ, Sílvia. Geografía Física de Argentina en la Universidad de Buenos Aires. Aportes a la cuestión ambiental. In: Congreso de Geografía Física, Puerto Vallarta, México, 2004.

${ }^{11}$ NATENZON, 1998, op. cit.

${ }^{12}$ NATENZON, 1998, op. cit. 
${ }^{13}$ MORIN, Edgar. El método. Tomos I a VII. Madrid: Editorial Cátedra, 1998; GARCÍA, Rolando. El conocimiento en construcción. De las formulaciones de Jean Piaget a la teoría de los sistemas complejos. España: Gedisa, 2000.

${ }^{14}$ MIRAGLIA, op. cit., seguindo a linha das pesquisas realizadas pela equipe de trabalho dirigida pelo Juan Lombardo e com critérios desenvolvidos independentemente.

${ }^{15}$ LOMBARDO, Juan Donato; VIRGILIO, María Mercedes Di. La conformación del espacio urbano en un país de economía emergente. Ciudad y territorio, España, n. 138, p 589-616, 2003.

${ }^{16}$ LOMBARDO, Juan D.; CATENAZZI, Andrea. La cuestión urbana en la RMBA. Buenos Aires: Ediciones al Margen, 2002.

${ }^{17}$ NATENZON, 1998, op. cit.

${ }^{18}$ NAGGY, Mariano, comunicação pessoal, 2010.

${ }^{19}$ Ibidem.

${ }^{20}$ CUNILL GRAU, Pedro. Las transformaciones del espacio geohistórico latino-americano, 1930-1990. Cidade do México: Fondo de Cultura Económica, 2004. (Serie Fideicomiso Historia de las Américas).

${ }^{21}$ Para uma discussão mais aprofundada dos impactos ambientais das cidades modernas vorazes, ver CRONON, William. Nature's Metropolis: Chicago and the Great West. Nova York: W. W. Norton, 1991.

Artigo recebido em dezembro de 2013. Aceito em dezembro de 2013. 